\title{
Recognition of andropausic symptoms
}

\author{
Jean Mailhot MD, CSPQ (Endocrinology) \\ "A new sign of prestige and status will be a person's ability to exude a healthy disposition... \\ lacking signs of premature aging and wear."(1)
}

J Mailhot. Recognition of andropausic symptoms. J Sex Reprod Med 2001;1(2):75-77.

The aging phenomenon in men is the result of a process that is different from that in women; however, the clinical manifestations may be similar. The term 'andropause' is used to define partial testosterone deficiency in the aging male. The symptoms of andropause are numerous, and are related to decreased multihormonal concentration and efficacy. To date, testosterone deficiency seems to be a significant factor in the male aging process. The present paper reviews screening, diagnosis and the symptoms of andropause.

Key Words: Cognitive function; Masculinity; Mood disorders; Nervous symptoms; Sexuality; Vasomotor symptoms; Virility

\section{Reconnaître les symptômes de l'andropause}

RÉSUMÉ : Le processus de vieillissement chez l'homme diffère de celui observé chez la femme; toutefois, les manifestations cliniques peuvent se ressembler. On entend par « andropause » le déficit partiel en testostérone qui s'installe chez l'homme vieillissant. Les symptômes de l'andropause sont variés et liés à une diminution de la concentration et de l'efficacité d'un large éventail d'hormones. Le déficit en testostérone semble, jusqu'à maintenant, jouer un rôle important dans le processus de vieillissement chez l'homme. Le présent article porte sur le dépistage, le diagnostic et les symptômes de l'andropause.
C limacteric symptoms in women, as well as the term 'menopause', are well recognized y the medical community. Menopause relates to a patient's clinical status and is confirmed by a biological test. The aging phenomenon in men is the result of a process that is different from that in women; however, the clinical manifestations may be similar. The term 'andropause' is used to define a partial testosterone deficiency in the aging male. Although the term is basically a misnomer, its use has been accepted by both health professionnals and lay people. Attempts to find a more accurate term, such as andropenia, testopenia, partial androgen deficiency in the aging male, androgen deficiency in aging males, aging male's symptoms (AMS) and male menopause, have proved to be unsuccessful.

\section{DEFINITION}

Andropause is a clinical entity that is related to aging. It is not a disease, but rather, a slow physiological process that is secondary to decreases in multihormonal concentration, multihormonal production and multihormonal efficacy, and a decreased capacity of receptors to respond to stimuli. The hormones testosterone, luteinizing hormone, follicle-stimulating hormone, growth hormone, dehydroepiandrosterone), (dehydroepiandrosterone sulfate), androstenedione, melatonin and estradiol have been studied.

\section{SCREENING FOR ANDROPAUSE}

Morley's questionnaire (2) is the only known and validated questionnaire that is used as a screening test for 
TABLE 1

Morley's screening questionnaire for andropause

1. Do you have a decrease in libido (sex drive)?

2. Do you have a lack of energy?

3. Do you have a decrease in strength and/or endurance?

4. Have you lost height?

5. Have you noticed a decreased 'enjoyment' of life?

6. Are you sad and/or grumpy?

7. Are your erections less strong?

8. Have you noted a recent deterioration in your ability to play sports?

9. Are you falling asleep after dinner?

10. Has there been a recent deterioration in your work performance?

Data from reference 2

andropause. If the test result is negative, andropause can be ruled out as a diagnosis. For the test to be positive, a male patient must answer 'yes' to question 1 or 7 , or to any other three questions (Table 1).

After the questionnaire (the first step toward diagnosing andropause) is completed, it is necessary to follow good clinical practice guidelines by completing a clinical evaluation, ruling out any other disease with similar symptoms and confirming the diagnosis by a specific laboratory test (the latter is discussed by Dr Brisson on pages 78 to 80 in the present issue).

\section{CLINICAL DIAGNOSIS OF ANDROPAUSE}

The symptoms of andropause can be related to testosterone target organ (brain, skin, muscle, liver, synovial tissue, kidney, male sex organs, bone marrow and bone) deficiencies; however, has this correlation proven to be true or reliable? Suggested answers in published articles are regularly confirmed by recent research conclusions, but the final and most accurate answer to the above question awaits future research findings.

In 1998, the Canadian Andropause Society published practice recommendations for screening, monitoring and treating men affected by andropause (3). The recommendations included a list of symptoms that are classified into four areas of investigation. In 1999, Heinemann et al (4) suggested a new AMS rating scale. The scale was translated into French and adapted by Drs P Alarie and R Villeneuve; it is undergoing validation. In 2001, Heinemann et al (5) published the results of the validation process for the English version of the AMS questionnaire.

In the questionnaires and list of symptoms of andropause listed above, gonadal decline-related clinical manifestations remain fairly constant (6-9). However, Dobs et al (10) found that men with idiopathic low testosterone, compared with men with a pituitary tumour, complained more of impotence, erectile dysfunction and depression.

\section{SYMPTOMS OF ANDROPAUSE}

As noted by McKinley (11), because aging is a multifactorial phenomenon, a multidisciplinary management approach to andropause is required and is richly rewarding. In a work-
TABLE 2

Clinical symptoms of andropause classified according to four areas of investigation

Vasomotor and nervous syptoms
Hot flushes
Unexplained episodes of sweating
Insomnia
Nervousness
Mood disorders
Sadness and grumpiness
Lethargy, irritability
Decreased sense of well-being
Low mental energy (unusual fright and anxiety, decreased capacity to
make decisions, delayed actvities)
Pessimism and proneness to solitude
Depressive symptoms
Difficulties with short term memory
Masculinity and virility
Decreased vigor and physical activity
Frequent arthralgias and myalgias
Diminished muscle mass and strength
Abdominal obesity
Loss of sexual body hair
Sexuality
Decreased interest or desire for sex leading to decreased sexual
prerformance and activity
Decreased ejaculation (weakness and decreased volume)
Decreased quality of orgasm
Decreased sensibility of external genitalia

shop on andropause (12), the Quebec Task Force on Andropause outlined the following aspects that physicians must keep in mind when evaluating and trying to understand andropause.

- Andropause symptoms may be present with or without erectile dysfunction.

- Symptoms are usually progressive.

- There is wide inter- and intravariation of symptoms in men.

- Self-perception of andropause symptoms is influenced by a patient's basal health status.

Based on the author's experience and the experience of clinicians involved in the management of andropause, the three most frequent sypmtoms of andropause are hot flushes, decreased global well-being and decreased sexual desire. The numerous clinical manifestations are mostly testopenic symptoms that can be classified according to several areas of investigation (Table 2).

Excluding erectile dysfunction, the similarity of aging symptoms in men and women has been recognized for 
over 50 years. However, as stated by Heinemann et al (13), women report more symptoms than men, men mention symptoms only if they are specifically asked about them, and the perception of symptoms by men and women changes with sex and age.

\section{CONCLUSION}

Andropause is a clinical entity. The symptoms of andropause are numerous, and are related to decreased multihormonal concentration and efficacy. To date, testosterone deficiency seems to be a significant factor in the male aging process. The clinical diagnosis of andropause combines the art of medicine with the thoroughness of scientific rigour. Time will bring the evidence-based medicine.

\section{REFERENCES}

1. Hesch RD. The health of the aging person. Aging Male 1999;2:129-30.

2. Morley JE, Charlton E, Patrick P, et al. Validation of a screening questionnaire for Androgen Deficiency in Aging Males (ADAM). Proceedings of the Endocrine Society. Toronto, 1998:136

3. Tremblay RR, Morales A. Canadian practice recommendations for screening, monitoring and treating men affected by andropause or partial androgen deficiency. Aging Male 1998;1:213-8.
4. Heinemenn LAJ, Zimmerman T, Vermeulen A, Thiel C, Hummel W. A new 'aging male's symptoms' rating scale. Aging Male 1999;2:105-14.

5. Heinemann LAJ, Saad F, Thiele K, Wood-Dauphinee S. The Aging Male's Symptoms rating scale: Cultural and linguistic validation into English. Aging Male 2001;4:14-22.

6. Nicopoulou SC, Adamopoulos DA. Gonadal decline-related manifestations in aging hospital doctors. Aging Male 2001:4:8-13.

7. Tenover JL. Testosterone and the aging male. J Androl 1997;18:103-6.

8. Morales A. Andropause, a misnomer for a true clinical entity. 7th International Congress of Andrology. Montreal, June 2001.

9. Vermeulen A. The male climacterium. Ann Med 1993;25:531-4.

10. Dobs AS, El-Dery S, Wand G, Wiederkehr M, Bell DSH, Mayo MS. Central hypgonadism: Distinguishing idiopathic low testosterone from pituitary tumors. Endocr Pract 1998;4:355-9.

11. McKinley JB. So you want to study male aging and health? Ten questions in search of an answer. 2nd International Congress on The Aging Male. Geneva, February 9 to 13, 2000.

12. Mailhot J, Tremblay RR, Brisson G. Quebec Task Force on Andropause. Workshop on Andropause. Montreal, May 2 1998.

13. Heinemann LAJ, Thiele C, Assmann A, Zimmerman T, Hummel W, Vermeulen A. Sex differences in 'climacteric symptoms' with increasing age? A hypothesis-generating analysis of cross-sectional population surveys. Aging Male 2000;3:124-31.

\section{INDUSTRY NEWS}

\section{LARGE NATIONAL SEXUAL HEALTH SURVEY PROBES BEDROOM HABITS OF CANADIANS}

The results of a large national Canadian survey on sexual health, commissioned by the Canadian Male Sexual Health Council, showed that poor sexual performance is the topic Canadians find most difficult to discuss with both their partners and their doctors. Based on the results of the survey, almost one-third of Canadian men suffer from erectile dysfunction (ED). Almost $40 \%$ of respondents with ED said that their condition has put some strain on their relationship and damaged their self-esteem.

"With this survey, we wanted to gather key information on sexual activity in order to help people become more comfortable talking about issues that commonly arise, particularly as we age," said Dr Gerald Brock, an associate professor at the Division of Urology at the University of Western Ontario, London, Ontario, and a member of the Canadian Male Sexual Health Council. "We also hoped to find out about sexual health issues that can impact people's day-to-day lives, be it decreased libido, performance anxiety or erectile difficulties," he added.

For the most part, Canadians believed that ED is caused by stress and other psychological factors, while one-quarter of respondents believed that it is caused by a serious health condition. "ED is often found in association with significant medical diseases, such as diabetes, depression and high blood pressure," said Dr Brock. "Considering that there are safe and effective treatment options available, we hope that the results of the survey will correct the misconceptions about ED and encourage Canadian men to talk with their partners and physicians."

The survey also indicated that approximately $70 \%$ of sexually active men would feel comfortable taking silfenafil citrate (Viagra; Pfizer Canada Inc, Canada) if their physicians suggested it.

During the survey, 3009 interviews were conducted by telephone with men and women aged 18 years and older from across Canada. A sample of this size is reported to yield a maximum margin of error of $\pm 1.78 \%, 19$ times out of 20 . The survey was funded by an educational grant from Pfizer Canada Inc.

\section{VIAGRA RECEIVES CANADIAN DRUG AWARD}

Sildenafil citrate (Viagra; Pfizer Canada Inc, Canada), an oral treatment for erectile difficulties, received the prestigious Prix Galien Canada Innovative Drug Product Award. “This year's Prix Galien Canada for the Innovative Drug Product is given to a medication introduced in Canada in 1999 that is considered to be of significant help to Canadian male patients," said Dr Jaques Gagné, president of Prix Galien Canada. 